\title{
Correction to: Development and Evaluation of Geostatistical Methods for Non-Euclidean-Based Spatial Covariance Matrices
}

\author{
Benjamin J. K. Davis $^{1,2}$ - Frank C. Curriero ${ }^{1,2}$
}

Published online: 8 May 2019

(C) International Association for Mathematical Geosciences 2019

\section{Correction to: Math Geosci https://doi.org/10.1007/s11004-019-09791-y}

The original version of this article unfortunately contained a mistake in equation 9 .

The correct version of Eq. 9 is

$$
{\mathrm{CV}-\mathrm{R}^{2}}^{2}=1-\frac{\sum_{i=1}^{n}\left(y_{i}-\hat{y}_{i}\right)^{2}}{\sum_{i=1}^{n}\left(y_{i}-\bar{y}\right)^{2}} ; \quad \text { where } \bar{y}=\frac{1}{n} \sum_{i=1}^{n} y_{i} \text {. }
$$

Please note that the correct form of the equation was used during statistical computation and so the results remain unchanged.

The original article can be found online at https://doi.org/10.1007/s11004-019-09791-y.

$凶$ Benjamin J. K. Davis

Bdavis64@jhmi.edu

1 Department of Epidemiology, Johns Hopkins Bloomberg School of Public Health, Johns Hopkins University, 627 N. Washington Street, Room 2-A, Baltimore, MD 21205, USA

2 Spatial Science for Public Health Center, Johns Hopkins University, 615 N. Wolfe Street, Room E6541, Baltimore, MD 21205, USA 